Int. J. Electrochem. Sci., 14 (2019) $8819-8835$

\title{
Aminoethanesulfonic Acid- Based Blends for Inhibition of J55 Steel Corrosion in Simulated Oilfield Pickling Fluid
}

\author{
Xianming Liu ${ }^{1,2}$, Jiajia Jing ${ }^{3, *}$, Qiang $\mathrm{Fu}^{4}$, Qiong $\mathrm{Li}^{1}$, Su Li ${ }^{5}$, Yaguang $Q \mathrm{u}^{6}$, Ambrish Singh \\ ${ }^{1}$ School of Mechanical Engineering, Yangtze University, Jingzhou,434000, China. \\ ${ }^{2}$ Drilling \& Production Technology Research Institute, CCDE, CNPC, Guanghan 618000, China \\ ${ }^{3}$ Safety, Environment, Quality Supervision \& Testing Research Institute, CCDE, CNPC, Guanghan \\ 618000 , China. \\ ${ }^{4}$ PetroChina Southwest Oil \& Gasfield Company Engineering Technology Research Institute, \\ Chengdu, 610000, China. \\ ${ }^{5}$ Shunbei oil and gas management department, SINOPEC Xibei branch company, Urumchi, 830001, \\ China. \\ ${ }^{6}$ School of Petroleum Engineering, Yangtze University, Wuhan, 430100, China. \\ ${ }^{7}$ School of Materials Science and Engineering, Southwest Petroleum University, Chengdu, China. \\ *E-mail: jingjiajia88@163.com
}

doi: $10.20964 / 2019.09 .26$

Received: 25 March 2019 / Accepted: 19 May 2019 / Published: 31 July 2019

\begin{abstract}
As industries are more interested in patronizing non-toxic and ecofriendly inhibitors to preserve environment, two binary and a ternary blend have been formulated from 2-aminoethanesulphonic acid (2ASA) and some synergistic intensifiers. The blends have been demonstrated as efficient corrosion inhibitors in simulated pickling fluid for protection of J55 steel materials used in oilfield. Small concentration $\left(10^{-3} \mathrm{M}\right)$ of the base compound, 2ASA, was $96.4 \%$ efficient at $30^{\circ} \mathrm{C}$ but far less efficient at high temperature $\left(90^{\circ} \mathrm{C}\right)$. Due to synergistic effects of the compounds used to formulate the blends, it was possible to record efficiency up to $87.8 \%$ at $90{ }^{\circ} \mathrm{C}$ for one of the blends containing potassium iodide (KI) and dipotassium hydrogen phosphate (DPHP). Adsorption of 2ASA molecules was spontaneous, exothermic and involves monolayer of physisorbed molecules on J55 steel surface as best approximated by Langmuir adsorption model. Tafel measurements confirm that 2ASA behaves as mixed type inhibitor with domino inhibitive influence on anodic half reaction. FTIR and EDAX studies confirm that adsorption of 2ASA is facilitated by $\mathrm{N}, \mathrm{S}$, and $\mathrm{O}$ functionalities. Formation of surface adsorbed 2ASA film was visibly observed via scanning electron microscopy (SEM). Inhibition efficiencies of 2ASA were determined by weight loss, electrochemical impedance spectroscopy (EIS) and potentiodynamic polarization (PDP) techniques and results were consistent and comparable. 2ASA and its blends could find application as alternative ecofriendly corrosion inhibitors for pickling and similar acidizing operations in the oilfield.
\end{abstract}


Keywords: 2-aminoethanesulphonic acid, pickling corrosion inhibitor, adsorption, inhibitor blends, SEM/EDS, EIS.

\section{$\underline{\text { FULL TEXT }}$}

(C) 2019 The Authors. Published by ESG (www.electrochemsci.org). This article is an open access article distributed under the terms and conditions of the Creative Commons Attribution license (http://creativecommons.org/licenses/by/4.0/). 